\title{
Оперативная техника
}

УДК 617.76-089.044

\section{ТЕХНИКА ЭВИСЦЕРОЭНУКЛЕАЦИИ И ФОРМИРОВАНИЯ ОПОРНО-ДВИГАТЕЛЬНОЙ КУЛЬТИ С ОТКРЫТОЙ РОГОВИЦЕЙ}

\author{
С. А. Рыков, д. мед. наук, проф., Н. В. Торчинская, канд. мед. наук, И. В. Симчук, врач \\ Киевская городская клиническая офтальмологическая больница «Центр микрохирургии глаза»
}

В статті викладено нову техніку евісцероенуклеації з формуванням опорно-рухливої кукси з відкритою рогівкою за допомогою сферичного імплантату з ПММА та можливістю використання кольорової м'якої контактної лінзи для протезування. Авторами детально описані особливості техніки операції, приведені відмінності нової техніки від інших сучасних технік евісцероенуклеації.

Відмічено, що запропоновані вдосконалення оперативної техніки евісцероенуклеації значно скорочують тривалість операції, зменшують пошкодження м'язово-фасціального апарату орбіти, покращують результати косметичного протезування, а наявність відкритої рогівки на поверхні опорнорухливої кукси приводить до відмови пацієнтів від очного протезу на користь косметичної м'якої контактної лінзи.

Ключевые слова: эвисцероэнуклеация, опорно-двигательная культя, косметическое протезирование.

Ключові слова: евісцероенуклеація, опорно-рухлива кукса, косметичне протезування.

ВВЕДЕНИЕ. Несмотря на развитие офтальмологии за последние десятилетия (появление новых эффективных препаратов для консервативной терапии, усовершенствование инструментария и методик оперативных вмешательств) в некоторых случаях офтальмохирургу все-таки приходится сталкиваться с необходимостью удаления глаза. Задача офтальмолога в этой ситуации заключается в минимизации хирургической травмы, создании оптимальных условий для косметического протезирования.

Использование косметического протеза пациентом имеет ряд недостатков:

- дискомфортные ощущения со стороны конъюнктивальной полости, вызванные несоответствием формы и размера протеза;

- неполная передача подвижности с опорнодвигательной культи на протез;

- необходимость применения дезинфицирующих растворов для обработки протеза и промывания конъюнктивальной полости.

Цель исследования: разработка новой, менее травматичной техники эвисцероэнуклеации и формирования опорно-двигательной культи (ОДК) с открытой роговицей и возможностью использования цветной контактной линзы для протезирования.

МАТЕРИАЛ И МЕТОДЫ ИССЛЕДОВАНИЯ. По разработанной методике (Декларационный патент Украины на полезную модель № 57060 от 10.02.2011) в КГКОБ «Центр микрохирургии глаза» прооперировано 35 человек в возрасте от 25 до 75 лет, среди них мужчин - 15, женщин -
20. У 22 пациентов был установлен диагноз - болящая терминальная вторичная глаукома, у 13 человек - угроза симпатической офтальмии после проникающих ранений. Всем больным до операции было проведено клиническое обследование: визометрия, биомикроскопия с оценкой состояния роговицы, периметрия, тонометрия, эхобиометрия с определением длины передне-задней оси (ПЗО) и ультразвуковое сканирование на предмет исключения внутриглазной опухоли. Для проведения эвисцероэнуклеации по новой методике отобраны пациенты, у которых острота зрения удаляемого глаза - 0 (ноль), при биомикроскопии роговицы не обнаружено ее истончения и перфорации, а при эхобиометрии длина ПЗО составила 22-24 мм. В предоперационной подготовке выполнялось введение 4 мл 12,5\% раствора этамзилата внутримышечно и 1,0 г цефтриаксона внутривенно (цефтриаксон - после предварительной внутрикожной пробы в случае ее негативного результата).

Техника операции. Все этапы оперативного вмешательства выполняются на микрохирургическом уровне. После ретробульбарной анестезии разрез конъюнктивы по лимбу и отсепаровка конъюнктивы и теноновой оболочки до экватора глазного яблока. Глазное яблоко удерживается в нужном положении с помощью хирургического пинцета. Посредством дугообразного разреза склеры на 2/3 окружности на расстоянии 4 мм от лимба формируется округлый лоскут, основанием к нижнему конъюнктивальному своду (рис. 1). Выполняется эвисцерация, внутреннюю поверхность склеры очищают от остатков сосудистой оболочки и обрабатывают $5 \%$ спиртовым раствором йода. Для улучшения визуализации на последующих этапах края склерального разреза помещают под векорасширитель. В заднем полюсе склеры вокруг диска зрительного нерва

(C) С. А. Рыков, Н. В. Торчинская, И. В. Симчук, 2011 
на расстоянии 2-3 мм от него выполняется дугообразный разрез склеры на $2 / 3$ окружности. Под зрительный нерв проводится изогнутый крючок с лигатурой (фото 1). Зрительный нерв перевязывается вместе с артерио-венозным пучком. Энуклеационные ножницы проводят через полость склеры и разрез в ее заднем полюсе, проводится невротомия выше места наложения лигатуры (рис. 2). Гемостаза обычно не требуется. В полость склеры для формирования ОДК помещается сферический имплантат из ПММА диаметром 18-20 мм 3. Ф.Веселовской, Н. Н. Шадриной (Декларационный патент Украины № 36962А, 2001г). Корнеосклеральный лоскут укладывается на место (рис. 3), на дугообразный склеральный разрез накладываются узловые швы (викрил 8-0) (рис. 4). Конъюнктива и тенонова оболочка фиксируются вокруг лимба кисетным швом (викрил 8-0). Для дополнительной фиксации конъюнктивы к эписклере накладывается 1-3 П-образных шва. Роговица остается открытой на поверхности опорно-двигательной культи (фото 2). Парабульбарно вводится 1 мл 0,4 \% раствора дексаметазона. В конъюнктивальную полость закладывается мазь с антибиотиком. Асептическая монокулярная повязка без компрессии.

В послеоперационном периоде для профилактики инфекционных осложнений выполняются инстилляции антибиотиков и применяется пероральный прием фторхинолонов в течение 5 дней, для уменышения аллергической реакции тканей на имплантат применяются инстилляции кортикостероидов, парабульбарные инъекции $0,4 \%$ раствора дексаметазона. Амбулаторное лечение проводится в среднем до одного месяца.

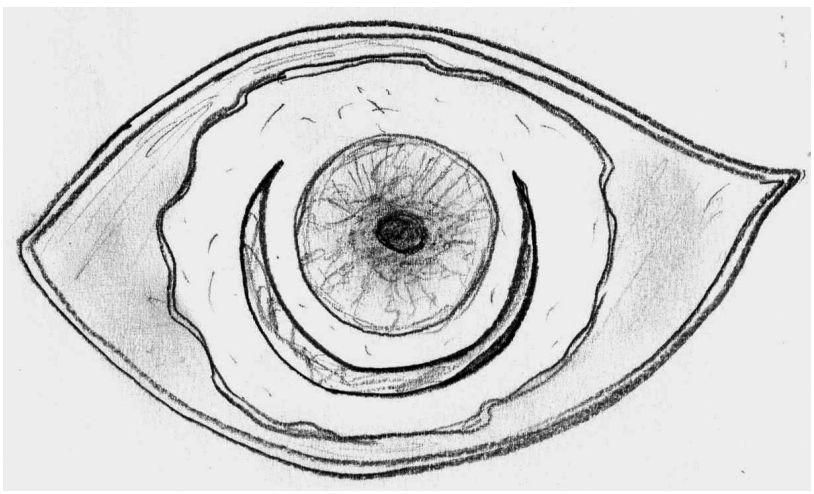

Рис. 1. Дугообразный разрез склеры на расстоянии 4 мм от лимба с формированием корнеосклерального лоскута основанием к нижнему своду.

После операции у всех пациентов оценивали реакцию мягких тканей, определяли ширину глазной щели, положение вершины роговицы ОДК с помощью экзофтальмометра по методу И. И. Калачова, подвижность ОДК по методу М. Т. Катаева - И. А. Филатовой - М. П. Харлампиди в $1,3,7,14$ сутки и через 1, 3, 6 месяцев после операции. Через 2-4 недели после операции пациент направлялся на протезирование с установкой косметической контактной линзы. В качестве основы для окрашивания использовалась годичная мягкая контактная линза производства фирмы «Ликон» «Lileya 40» (62 \% Hema).

РЕЗУЛЬТАТЫ. У всех пациентов оперативные вмешательства по разработанной методике выпол- нены без осложнений. Послеоперационный период протекал без особенностей. Реакция мягких тканей орбиты на хирургическое вмешательство и имплантат в виде гиперемии и отека век и конъюнктивы оценивалась по следующей шкале: 0 - реакция мягких тканей отсутствует, 1 - слабо выражена, 2 умеренно выражена, 3 - выражена. Степень выраженности признаков оценивали в первые, третьи, седьмые и 14 сутки после операции.

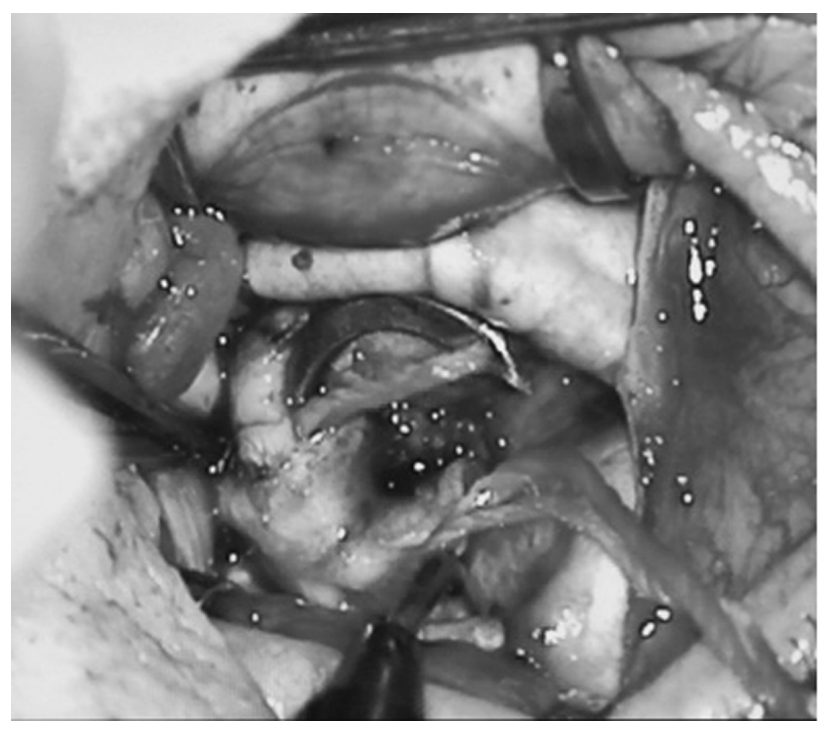

Фото 1. Проведение изогнутого крючка с лигатурой вокруг зрительного нерва и сосудистого пучка.

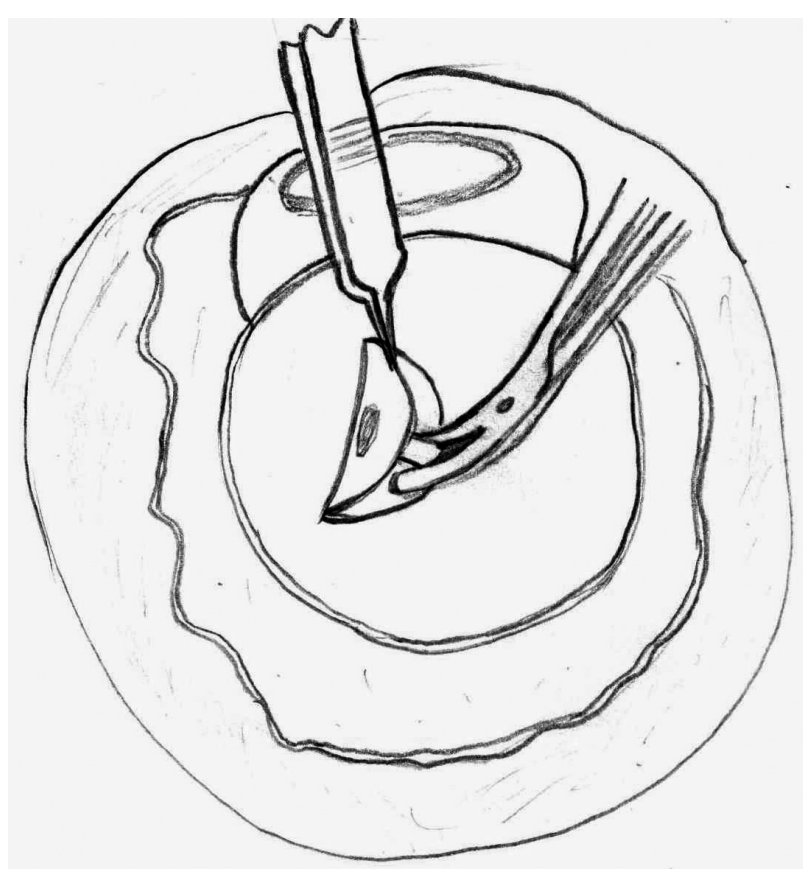

Рис. 2. Пересечение зрительного нерва трансбульбарным доступом.

На первые сутки после операции реакция мягких тканей была слабо выражена у 23 (65,7 \%) пациентов, умеренно выражена - у 12 (34,3 \%). На 
седьмые сутки у пяти (14,3 \%) пациентов был выявлен умеренный отек конъюнктивы, у трех $(8,6 \%)$ пациентов - выраженный отек за счет появления аллергической реакции на имплантат. К 14 суткам реакция мягких тканей отсутствовала у 19 (54,3\%) пациентов, была слабо выражена у 16 (45,7 \%) пациентов. Полностью гиперемия конъюнктивы исчезала через один месяц после операции.

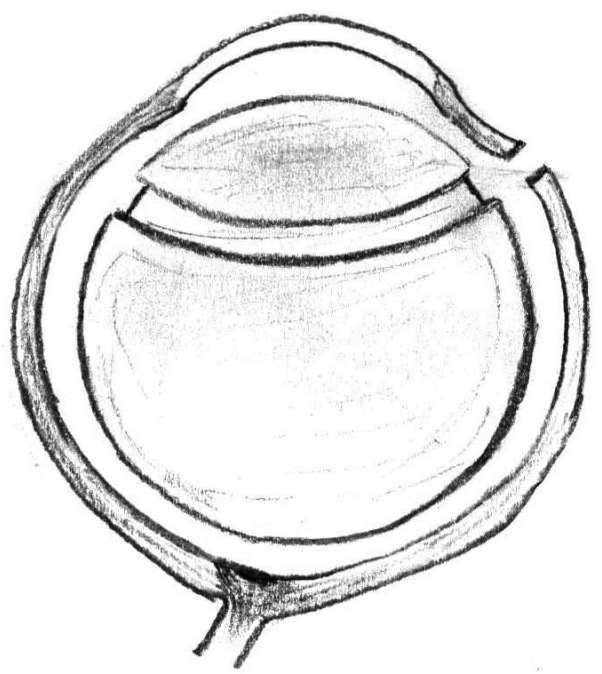

Рис. 3. Сферический имплантат расположен в склеральном «бокале», сверху укладывается на место корнеосклеральный лоскут.

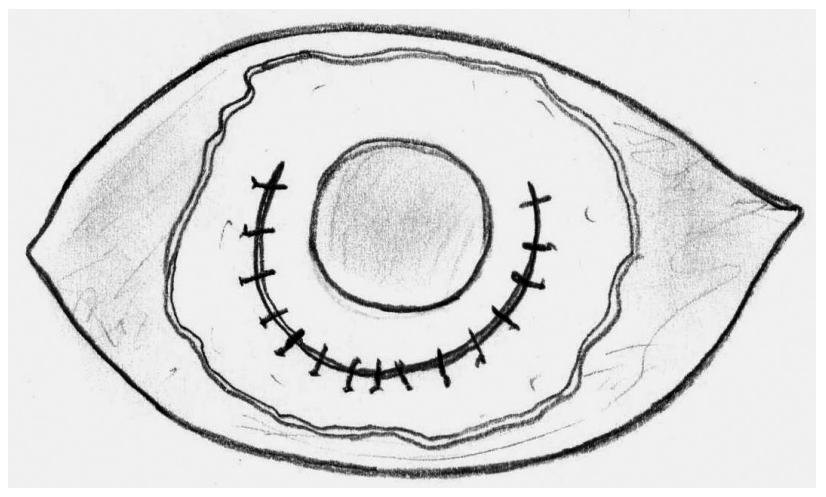

Рис. 4. Дугообразный склеральный разрез адаптирован узловыми швами.

Ретробульбарная гематома в послеоперационном периоде не встречалась ни у одного пациента.

Разница между шириной глазной щели здорового глаза и ОДК отсутствовала у 28 (80 \%) пациентов, составляла 1 мм - у пяти $(14,3 \%)$ пациентов, 2 мм - у двух $(5,7 \%)$ пациентов через 1 месяц после эвисцероэнуклеации.

Спустя месяц после операции центр роговицы ОДК был расположен на уровне центра роговицы здорового глаза у 7 (20 \%) пациентов, кзади на 1мм от центра роговицы здорового глаза - у 25 (71,4\%) пациентов, кзади на 2 мм - у трех $(8,6 \%)$ пациентов.

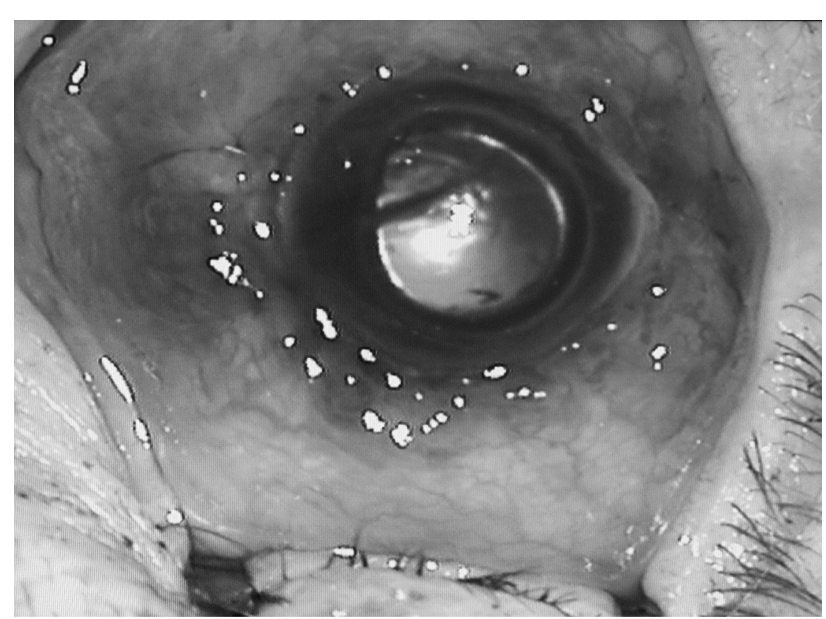

Фото 2. Фиксация конъюнктивы по лимбу, роговица открыта на поверхности опорно-двигательной культи.

Суммарная подвижность ОДК через 1 месяц после операции колебалась от $148 €$ до 154є и составила в среднем $(152 \pm 1,8) \epsilon$.

За 6 месяцев наблюдения после операции ни у одного пациента не отмечено расхождения швов и оголения имплантата.

Эпителизация роговицы сохранялась во все сроки наблюдения. Развитие васкуляризации роговицы начиналось через 3-6 недель после операции в виде глубокой васкуляризации, что не влияло на субъективные ощущения пациентов и возможность ношения цветной контактной линзы.

\section{ВЫВОДЫ}

1. Техника предложенной операции является менее травматичной за счет ряда факторов:

А) Минимизирована хирургическая травма экстраокулярных мышц и орбитальной клетчатки, так как фиксация глазного яблока выполняется с помощью пинцета без наложения швов на прямые мышцы, доступ для проведення невротомии осуществляется через полость склеры и разрез в ее заднем полюсе.

Б) При пересечении зрительного нерва и сосудистого пучка с предшествующим наложением лигатуры отсутствует кровотечение. Отсутствие ретробульбарной гематомы сокращает сроки послеоперационной реабилитации пациентов.

В) Выполнение разреза склеры на расстоянии 4 мм от лимба позволяет вводить имплантат в склеральную капсулу без расширения ее меридиональными разрезами.

Г) Не выполняется фиксация имплантата к склере.

2. Хороший косметический эффект новой техники эвисцероэнуклеации обеспечивают:

А) Подвижность опорно-двигательной культи на уровне здорового глаза за счет сохранения всех экстраокулярных мышц, включая косые мышцы. 
Б) Наличие нормальной ширины глазной щели и отсутствие птоза верхнего века без установки косметического протеза, что достигается использованием имплантатов диаметром 20мм, приближенным к длине ПЗО здорового глаза.

В) Наличие открытой эпителизированной роговицы на поверхности ОДК и применение косметической цветной контактной линзы для протезирования.

3. Улучшается психологическая адаптация пациентов к перенесенному оперативному вмешательству в связи с визуальным эффектом сохранения глазного яблока.

\section{ЛИТЕРАТУРА}

1. Волков В. В., Бржеский В. В., Ушаков Н. А. Офтальмохирургия с использованием полимеров. - Спб.: Гиппократ, 2003. - С.349-382.

2. Веселовська 3. Ф., Шадріна Н. М., Веселовська Н. М. Ефективність нової технології формуван- ня опорно-рухливої кукси після видалення очного яблука з застосуванням комбінованого імплантату // Офтальмологічний журнал. - 2004. - № 3. - С.3235.

3. Ольшевский И. Е., Канафьянова Е. Г., Кудайбергерова Г. Б. Влияние техники операции по удалению глазного яблока на динамические свойства постэнуклеационной культи // Збірник наукових праць співробітників КМАПО ім. П. Л. Шупика. - вип.13, кн.4. - Київ, 2004. - С.532-537.

4. Харлампиди М. П. Разработка оптимальных способов энуклеации для улучшения косметических показателей глазного протезирования: Дис....канд. мед. наук. - М., 2002.

5. Arruga H. Problem of orbital implants after enucleation // Brit. J. Ophthal. - 1995. - Vol. 39. - № 10. - P.315316.

6. Custer P. L., Kennedy R. H., Woog J. J. and others. Orbital implants in enucleation surgery // Ophthalmology. 2003. - Vol.110. - P.2054-2061.

Поступила 17.05.2011

Рецензент д-р мед.наук А. П. Малецкий

\section{A TECHNIQUE OF EVISCLEROENUCLEATION AND FORMATION OF SUPPORTING-MOBILE STUMP WITH OPEN CORNEA}

Rikov S. O., Torchinskaya N.V, Simchuk I. V.

\section{Kiev, Ukraine}

The paper describes a new technique of evisceroenucleation and formation of supporting-mobile stump with open cornea using a spherical polymethylmetacrylate implant and the possibility of using colored soft contact lenses for the prosthesis. The authors described in detail peculiarities of the technology, gave the differences of the new technique from other modern techniques of evisceroenucleation. It is noted that the proposed improvements of the evisceroenucleation technique significantly reduce the duration of intervention, reduce damage to the orbital muscle-fascial complex, improve cosmetic results of the prosthesis, lead to patients' refusal from ocular prosthesis in favor of cosmetic soft contact lenses. 